\title{
Therapeutic Potential of Thrombomodulin in Renal Fibrosis of Nephrotoxic Serum Nephritis in Wistar-Kyoto Rats
}

\author{
Nobuhiro Kanazawa Masayuki lyoda Shohei Tachibana Kei Matsumoto \\ Yukihiro Wada Taihei Suzuki Ken Iseri Takanori Shibata \\ Division of Nephrology, Department of Medicine, Showa University School of Medicine, \\ Tokyo, Japan
}

\section{Keywords}

Thrombomodulin · Chronic kidney disease - Renal fibrosis · Nephrotoxic serum nephritis .

Protease-activated receptor

\begin{abstract}
Background: Recombinant human soluble thrombomodulin (rhTM) was approved in 2008 and has been used for treatment of disseminated intravascular coagulation in Japan. The antifibrotic effects of rhTM in acute exacerbation of idiopathic pulmonary fibrosis are well established, but the therapeutic potential of rhTM in renal fibrosis remains poorly understood. Methods: Nephrotoxic serum nephritis (NTS-N) was induced in 22 female Wistar-Kyoto (WKY) rats on day 0 . Rats were administered either rhTM or vehicle intraperitoneally, every day from day 4 to day 55. Rats were sacrificed on day 56 when renal fibrosis was established and renal morphological investigations were performed. In vitro, rat renal fibroblasts (NRK-49F) were pretreated with rhTM or saline, and expression levels of profibrogenic gene induced by thrombin were analyzed by real-time reverse transcription polymerase chain reaction. Results: Compared to WKY-GN-vehicle rats, the body weights of WKY-GN-rhTM rats were significantly greater on day 55. By day 56, rhTM had significantly reduced serum creatinine levels in NTS-N. On the other hand, urinary protein excretion was comparable between the two treatment groups throughout the study. The percentage of Masson trichrome-positive areas in WKY-GN-rhTM rats was significantly lower compared to that in WKY-GN-vehicle rats. Glomerular fibrin deposition was significantly reduced in WKY-GN-rhTM rats. In addition, rhTM significantly reduced the renal cortical mRNA expression levels of TNF- $\alpha$, Toll-like receptor 4 , MYD88, TGF- $\beta$, $\alpha$ SMA, collagen I, collagen III, fibronectin, and protease-activated receptor 1
\end{abstract}




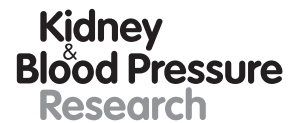

Kidney
Blood Pressure
Research

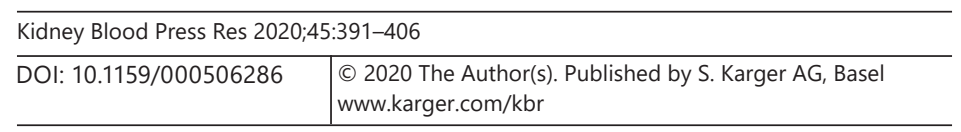

Kanazawa et al.: Thrombomodulin Attenuates Renal Fibrosis

(PAR1), a thrombin receptor. In vitro, thrombin stimulation of NRK-49F cells significantly enhanced the mRNA expression levels of $\alpha$ SMA and PAR1, and these upregulations were significantly reduced by pretreatment with rhTM. Conclusions: Administration of rhTM after establishment of crescentic glomerulonephritis (GN) attenuated the subsequent development of renal fibrosis in NTS-N, possibly in part by inhibiting thrombin-mediated fibrogenesis. Our results suggest that rhTM may offer a therapeutic option for limiting the progression of chronic kidney disease in crescentic GN.

(C) 2020 The Author(s)

Published by S. Karger AG, Basel

\section{Introduction}

Thrombomodulin (TM) is a glycoprotein present on the surface of endothelial cells in many organs, including the lungs, liver, and kidneys. TM regulates the coagulation pathway via inhibition of thrombin and activation of protein C. It also plays beneficial roles in inflammation, fibrinolysis, apoptosis, cell adhesion, and cell proliferation beyond the hemostatic system [1, 2]. Recombinant human soluble TM (rhTM) was approved in 2008 and has been used for treatment of disseminated intravascular coagulation in Japan. Recently, the antifibrotic efficacy of rhTM has been reported $[3,4]$. Several studies have shown its therapeutic effects on acute exacerbation of idiopathic pulmonary fibrosis, which is pathophysiologically characterized by extravascular and intra-alveolar thrombin activation and fibrin deposition following epithelial and endothelial injury $[5,6]$.

Renal fibrosis is regarded as the final common pathway in a wide variety of chronic kidney diseases [7, 8], characterized by glomerulosclerosis and tubulointerstitial fibrosis [9]. A significant correlation exists between renal functional outcome and histopathological changes of glomerulosclerosis and tubulointerstitial fibrosis [10-13]. Proliferation of fibroblasts and their activation into myofibroblasts represent key steps in renal fibrosis $[14,15]$. Protease-activated receptors (PARs) are members of a family of G protein-coupled receptors that are expressed on fibroblasts, tubular epithelial cells, endothelial cells, and mesangial cells $[16,17]$. These receptors are activated by endogenous serine proteases such as thrombin. They provide a molecular link between coagulation proteases and renal cell function, including inflammation, fibrogenesis, and extracellular matrix remodeling. Since TM-bound thrombin changes the substrate specificity of thrombin, rhTM seems to have some effect on PAR activation by thrombin.

Crescentic glomerulonephritis (GN) is characterized clinically by rapidly progressive renal failure and histologically by inflammatory cell infiltration in glomeruli and the tubulointerstitium as well as necrotizing crescentic glomerular lesions [18]. In Wistar-Kyoto (WKY) rats, rabbit antirat glomerular basement membrane (GBM) antiserum (nephrotoxic serum [NTS]) induces severe proliferative and necrotizing GN, with crescentic formations resembling human crescentic GN. The chronic phase of this model of anti-GBM GN has been used as a model to investigate the effect of drugs on pathophysiological events in the progression to end-stage renal disease [19-21].

We have previously reported that rhTM attenuated anti-GBM GN in WKY rats through anti-inflammatory effects [22]. rhTM inhibited the HMGB1/TLR/MYD88 signaling pathway and prevented early development of crescentic GN. In the clinical setting, however, patients with GN already have renal dysfunction and/or proteinuria when treatment starts. Therefore, in the present study, rhTM was administered to rats 4 days after the induction of nephritis at a time when necrotizing crescentic GN was being established [23]. Here, we describe the therapeutic effects of long-term rhTM treatment in the chronic phase of anti-GBM GN via inhibition of thrombin-mediated fibrogenesis. 


\section{Kidney \\ Blood Pressure \\ Research}

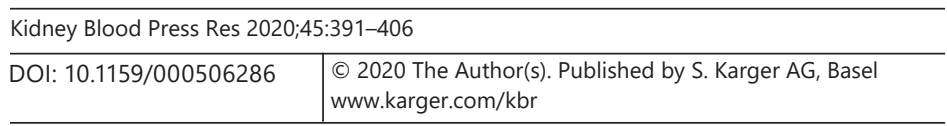

Kanazawa et al.: Thrombomodulin Attenuates Renal Fibrosis

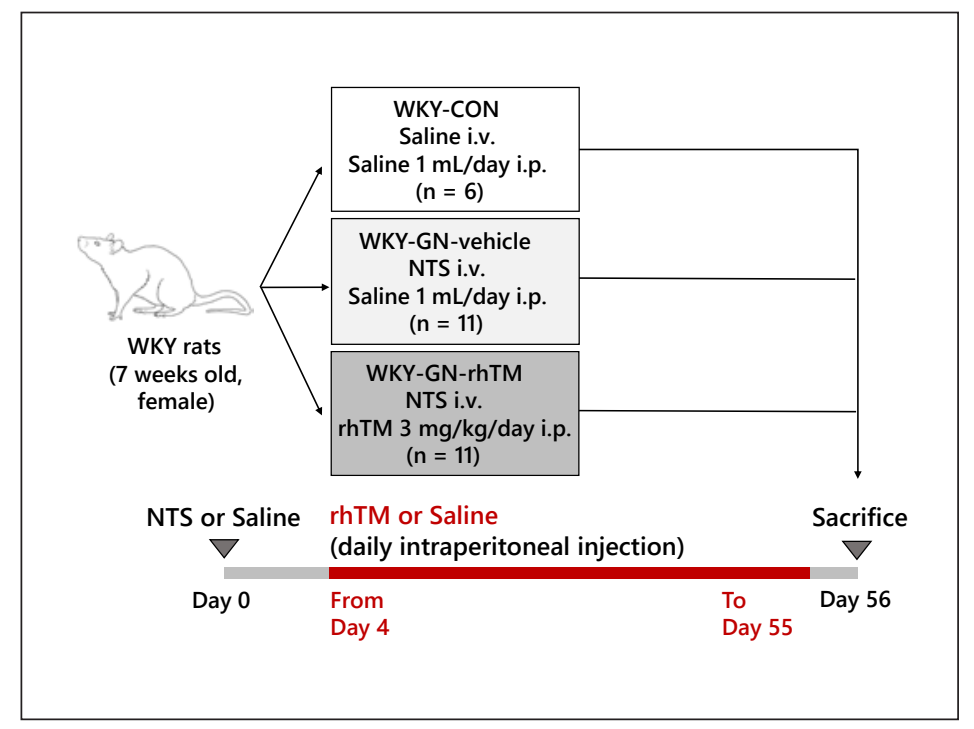

Fig. 1. Experimental design. Twenty-two female WKY rats were injected intravenously with $20 \mu \mathrm{L}$ of NTS on day 0 . Six control WKY rats received an equal volume of saline. Eleven WKY rats each were given rhTM $(3 \mathrm{mg} / \mathrm{kg}$ ) or vehicle daily by intraperitoneal injection, from day 4 to day 55 . The vehicle-treated group received an equal volume of saline. All rats were then sacrificed on day 56. CON, control; GN, glomerulonephritis; NTS, nephrotoxic serum; rhTM, recombinant human soluble thrombomodulin; WKY, Wistar-Kyoto.

\section{Materials and Methods}

\section{Nephrotoxic Serum}

GBM-reactive NTS was prepared as described earlier [24]. In brief, glomeruli were isolated from Wister rat kidneys by differential sieving and used to immunize rabbits. The activity and specificity of NTS were tested by indirect immunofluorescence microscopy of frozen sections of a normal rat kidney. Prior to injection into rats, the antiserum was decomplemented and absorbed with rat erythrocytes.

\section{Experimental Protocol}

Seven-week-old female WKY rats weighing $150 \mathrm{~g}$ were purchased from Charles River Japan (Atsugi, Japan) and housed in the animal care facility of Showa University $\left(25^{\circ} \mathrm{C}, 50 \%\right.$ relative humidity, 12-h dark/light cycle) with free access to food and water. A total of 22 female WKY rats were injected intravenously with $20 \mu \mathrm{L}$ of NTS to induce NTS nephritis (NTS-N) on day 0. Groups of animals were given either rhTM $(3 \mathrm{mg} / \mathrm{kg})$ (WKY-GN-rhTM) or an equal volume of saline (WKY-GN-vehicle) daily by intraperitoneal injection, from day 4 to day 55 (Fig. 1). All rats were sacrificed on day 56. Six female WKY rats were used as normal controls (WKY-CON). At the end of the study, rats were anesthetized, their blood was collected by cardiac puncture, and their kidneys were collected. Right kidneys were snap-frozen in liquid nitrogen for biochemical and gene expression analyses, and left kidneys were fixed in $2 \%$ paraformaldehyde/phosphate-buffered saline for histological analyses.

\section{Assessment of Biochemical Parameters}

For the analysis of proteinuria, rats were housed individually in metabolic cages for 24-h urine collection. Urine samples were collected the day before sacrifice. Urinary protein was determined using the biuret method. Serum creatinine $(\mathrm{Cr})$ levels were measured using an automated analyzer (Hitachi Corp., Tokyo, Japan) according to the manufacturer's instructions. Urinary neutrophil gelatinase-associated lipocalin (Abcam, Cambridge, UK), urinary $\mathrm{N}$-acetyl- $\beta$-D-glucosaminidase (NAG) activity (Diazyme; General Atomics, San Diego, CA, USA), and urinary $\beta 2$ microglobulin (Crystal Chem, Elk Grove Village, IL, USA) were measured using a commercially available assay kit according to the manufacturer's instructions. Since 


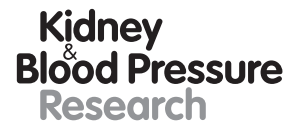

Kidney
Blood Pressure
Research

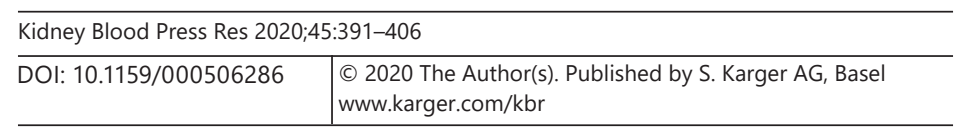

Kanazawa et al.: Thrombomodulin Attenuates Renal Fibrosis

urinary biomarker levels may be affected by urine volume, we normalized them to urinary Cr. The urinary NAG index was calculated using the following equation: NAG index (U/g $\mathrm{Cr})=$ urinary NAG activity $(\mathrm{U} / \mathrm{L}) /$ urinary $\mathrm{Cr}$ concentration $(\mathrm{g} / \mathrm{L})$.

\section{Quantification of Urinary rhTM Levels}

The levels of urinary rhTM were determined by a commercially available enzyme-linked immunosorbent assay kit (R\&D Systems, Minneapolis, MN, USA) according to the manufacturer's instructions.

\section{Light Microscopy}

Tissue fixed in $2 \%$ paraformaldehyde/phosphate-buffered saline was embedded in paraffin using routine protocols. Paraffin-embedded materials were sectioned at $2 \mu \mathrm{m}$ for routine staining with Masson trichrome stain, and $1-\mu \mathrm{m}$-thick sections were used for periodic acid methenamine silver stain. Glomerular sclerosis was assessed in 50 glomeruli on silverstained sections under $400 \times$ magnification using a semiquantitative score from 0 to $4(0$, no sclerosis; 1 , sclerosis in $\leq 25 \%$ of glomeruli; 2 , sclerosis in $>25-50 \%$ of glomeruli; 3 , sclerosis in $>50-75 \%$ of glomeruli; 4 , sclerosis in $>75 \%$ of glomeruli), and results were averaged. For evaluating tubulointerstitial fibrosis, five fields for each section (Masson trichrome stain) were evaluated at $200 \times$ magnification using the WinROOF image processing software (Mitani Corp., Tokyo, Japan). The fibrotic area was evaluated by counting the percentage of areas marked blue per field of cortex. All histological analyses were performed without knowledge of the origin of the slides, and mean values were calculated.

\section{Immunofluorescence}

The tissue snap-frozen in liquid nitrogen was cut into $4-\mu \mathrm{m}$-thick sections. Deposition of rat fibrin in the kidney sections was evaluated using a previously described method [23]. The extent of fibrin deposition in each glomerulus was graded for 50 glomeruli using a 4-point scale: 0 , absent; $1,<1 / 3 ; 2$, between $1 / 3$ and $2 / 3 ; 3,>2 / 3$ of the whole glomerulus. The mean score of 50 glomeruli was then calculated as the fibrin score.

\section{Immunohistochemistry}

The polyclonal antibody against rabbit antirat monocyte chemoattractant protein 1 (MCP-1) (Abcam) was used. Immunohistochemical staining for MCP-1 was performed using a method described earlier [23].

\section{Real-Time Reverse Transcription Polymerase Chain Reaction}

The gene expressions of rat TNF- $\alpha$, IL-6, MCP-1, Toll-like receptors (TLRs), MYD88, TGF- $\beta$, $\alpha$ SMA, collagen I, collagen III, fibronectin, PARs, and GAPDH were analyzed using realtime reverse transcription polymerase chain reaction (RT-PCR). In brief, kidney tissue (cortex) was homogenized using a TissueLyser (QIAGEN, Hilden, Germany), and total RNA was isolated using an RNeasy Fibrous Tissue Mini Kit (QIAGEN), in accordance with the manufacture's instructions. cDNA synthesis was carried out using the SuperScript First-Strand Synthesis System for RT-PCR (Invitrogen, Carlsbad, CA, USA). Predesigned TaqMan probe sets for the targets indicated above were purchased from Applied Biosystems (Foster City, CA, USA). Each probe has a fluorescent reporter dye (FAM) linked to its $5^{\prime}$ end and a downstream quencher dye (TAMRA) linked to its $3^{\prime}$ end. Each reaction consisted of $25 \mu \mathrm{L}$ containing $2 \times$ Universal Master Mix (Applied Biosystems), primers, labeled probes, and cDNA. The amplification conditions consisted of 40 cycles at $95^{\circ} \mathrm{C}$ for $15 \mathrm{~s}$ and $60^{\circ} \mathrm{C}$ for $1 \mathrm{~min}$ after incubation at $95^{\circ} \mathrm{C}$ for $10 \mathrm{~min}$. Amplification and fluorescence measurements were performed using the MicroAmp Optical 96-Well Reaction Plate on the ABI PRISM 7700 Sequence 


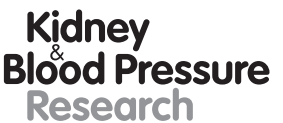

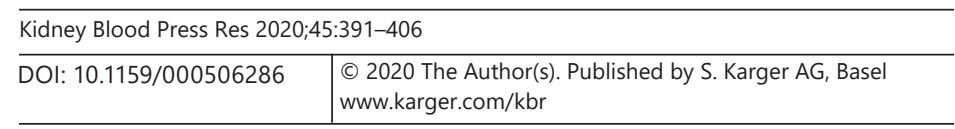

Kanazawa et al.: Thrombomodulin Attenuates Renal Fibrosis

Detection System (Applied Biosystems). mRNA expressions were normalized using GAPDH as an endogenous control to correct for the differences in the amount of total RNA added to each reaction.

\section{Cell Culture Studies}

Rat renal fibroblasts were obtained from American Type Culture Collection (NRK-49F; ATCC, Manassas, VA, USA). Cells were grown in DMEM/F12 containing 5\% FBS and $1 \%$ streptomycin-penicillin mixture in an atmosphere of $5 \% \mathrm{CO}_{2}$ and $95 \%$ air at $37^{\circ} \mathrm{C}$ in a humidified incubator. Cells at 70\% confluence were starved in a low-serum medium (0.5\% FBS) overnight, then pretreated with rhTM $(2 \mu \mathrm{g} / \mathrm{mL})$ or saline for $1 \mathrm{~h}$, followed by stimulation with thrombin (1 U/mL; Sigma-Aldrich, St. Louis, MO, USA) or 0.1\% BSA for $24 \mathrm{~h}$.

\section{Statistical Analyses}

Results are expressed as mean \pm SEM. The Mann-Whitney U test was used to evaluate differences in group means, and $p$ values $<0.05$ were considered statistically significant. All statistical analyses were performed using the PRISM statistical analysis software (GraphPad Software Inc., San Diego, CA, USA).

\section{Results}

\section{Effects of rhTM on Biochemical Parameters in Rats with Progressive Renal Failure}

The experimental design is described in Figure 1. After 8 weeks of treatment, the body weights were significantly greater for WKY-GN-rhTM rats than for WKY-CON rats $(p<0.05$; Fig. 2a). No significant changes in kidney weight were evident on day 56 (Fig. 2d). Serum $\mathrm{Cr}$ levels were significantly lower in WKY-GN-rhTM rats than in WKY-GN-vehicle rats at the end of the study ( $p<0.05$; Fig. 2 e). On the other hand, urinary protein excretion was comparable between the two treatment groups throughout the study (Fig. 2b). Urine volume was not significantly affected by rhTM in rats with NTS-N (Fig. 2c). The urinary $\beta 2$ microglobulin/ urinary $\mathrm{Cr}$ ratio, a marker of tubulointerstitial injury, declined in WKY-GN-rhTM rats on day $56(p<0.05$; Fig. 2h), whereas no significant differences were seen for other urinary biomarkers (Fig. 2f, g).

\section{Urinary Losses of rhTM}

Urinary protein excretion was observed in the rat with NTS-N on day 4 and gradually progressed. Since it was expected that some of rhTM leaked into urine, the level of urinary rhTM was determined by enzyme-linked immunosorbent assay. Urinary losses of rhTM reached $2.44 \pm 1.03 \mu \mathrm{g} /$ day in WKY-GN-rhTM rats on day 56 (Table 1). In contrast, rhTM was not detected in the urine samples of WKY-CON rats and WKY-vehicle rats on day 56.

\section{Effects of rhTM on Renal Histology in Rats with Progressive Renal Failure}

Figure 3 shows representative Masson trichrome and silver stainings of kidneys from the study groups. Renal histological findings were characterized by glomerulosclerosis and tubulointerstitial fibrosis. The glomerular sclerosis score was significantly increased in WKY-GNvehicle rats compared with WKY-CON rats $(p<0.01)$, and this increase was significantly reduced by rhTM treatment ( $p<0.05$; Fig. 3h). Histological evidence of tubulointerstitial fibrosis was evaluated by staining for collagen. Masson trichrome-positive areas were significantly increased in WKY-CON rats $(p<0.01)$, and rhTM treatment significantly reduced tubulointerstitial fibrosis $(p<0.05$; Fig. $3 g)$. 
a

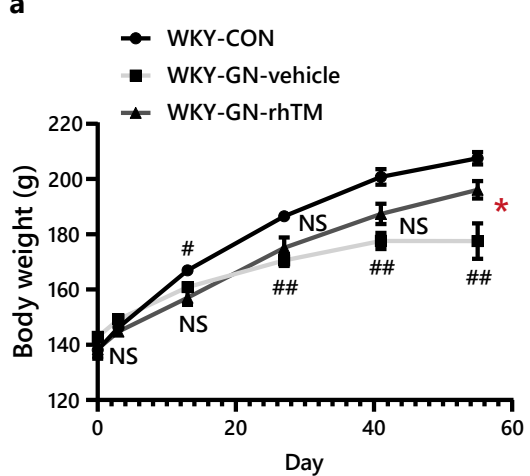

d

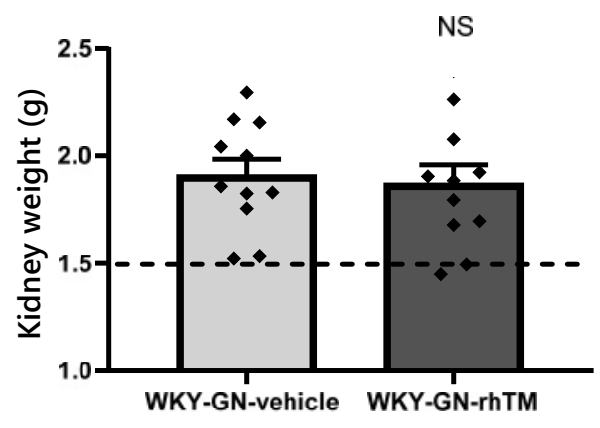

g

$\mathbf{f}$

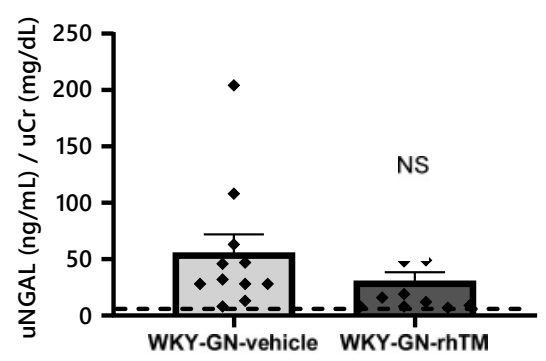

b
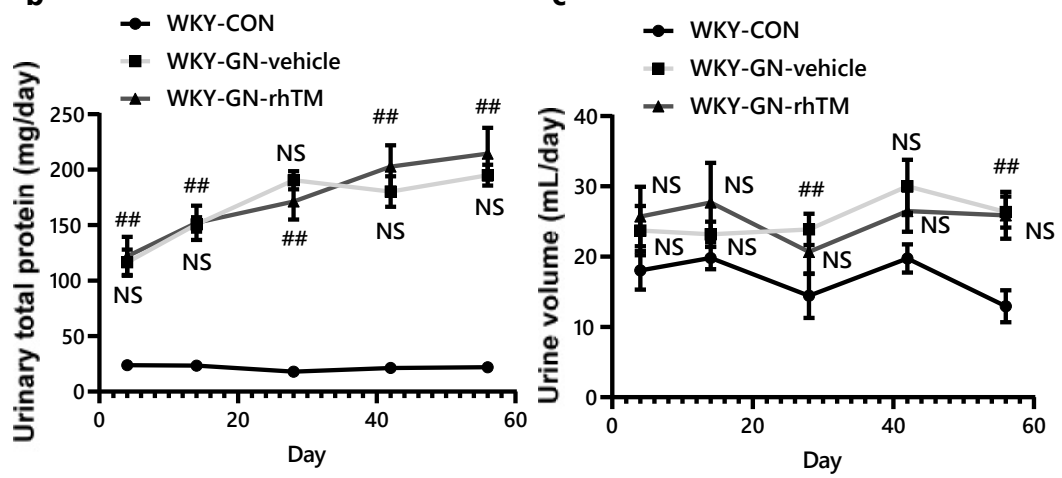

e

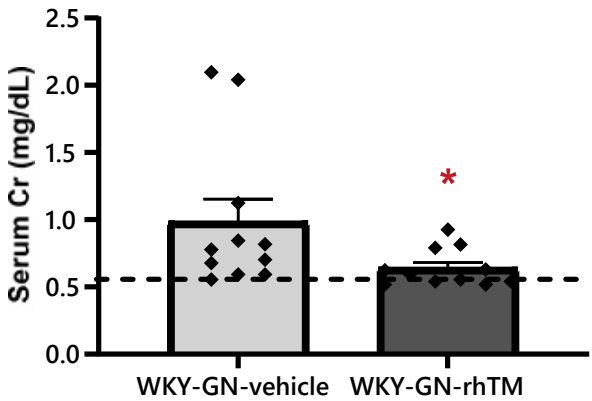

h
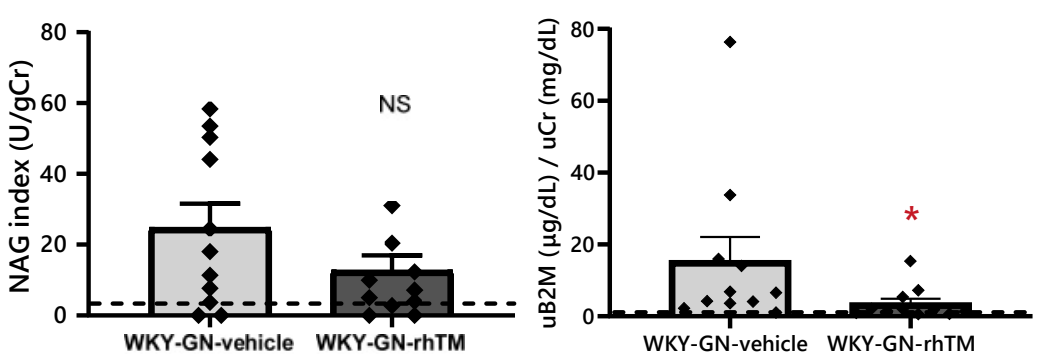

Fig. 2. rhTM preserved renal function and body weight in rats with progressive renal failure. Changes in body weight (a), urinary total protein (b), urine volume (c), kidney weight (d), serum Cr (e), uNGAL/uCr (f), NAG index (g), and uB2M/uCr (h) of WKY-CON, WKY-GN-rhTM, and WKY-GN-vehicle rats are shown. Horizontal dashed lines indicate the kidney weight, serum Cr level, uNGAL/uCr ratio, NAG index, and uB2M/uCr ratio in WKY-CON rats. Data are expressed as mean \pm SEM. NS, ${ }^{*} p<0.05$ : WKY-GN-rhTM versus WKY-GN-vehicle rats; NS, ${ }^{\#} p<0.05,{ }^{\# \#} p<0.01$ : WKY-GN-vehicle versus WKY-CON rats. CON, control; Cr, creatinine; GN, glomerulonephritis; NAG, N-acetyl- $\beta$-D-glucosaminidase; NS, not significant; rhTM, recombinant human soluble thrombomodulin; uB2M, urinary $\beta 2$ microglobulin; $\mathrm{uCr}$, urinary creatinine; uNGAL, urinary neutrophil gelatinase-associated lipocalin; WKY, Wistar-Kyoto. 


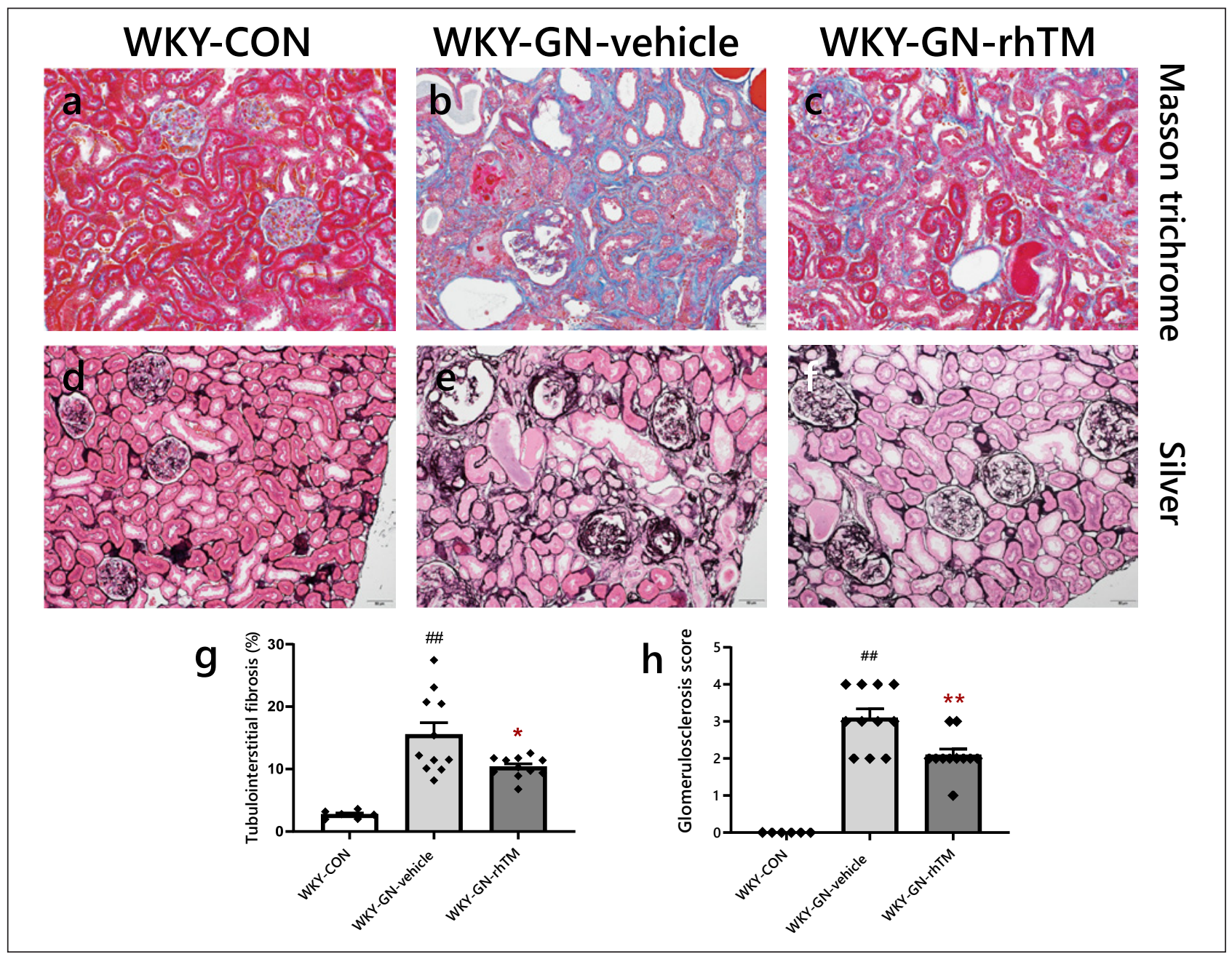

Fig. 3. Representative renal histology and quantification of tubulointerstitial fibrosis and glomerulosclerosis. a-f Renal histology on day 56 in WKY-CON rats (a, d), WKY-GN-vehicle rats (b, e), and WKY-GN-rhTM rats (c, f). Original magnification, $\times 200 . \mathbf{g}$, h Quantitative assessment of tubulointerstitial fibrosis $(\mathbf{g})$ and semiquantitative assessment of glomerulosclerosis (h) in each group. Each group contained 6 or 11 rats, and five fields or 50 glomeruli per rat were evaluated in a blinded manner. Data are expressed as mean \pm SEM. ${ }^{*} p<0.05,{ }^{* *} p<0.01$ : WKY-GN-rhTM versus WKY-GN-vehicle; ${ }^{\#} p<0.01$ : WKY-GN-vehicle versus WKY-CON. CON, control; GN, glomerulonephritis; rhTM, recombinant human soluble thrombomodulin; WKY, Wistar-Kyoto.

Table 1. Evaluation of urine volume and urinary rhTM levels at the end of the study

\begin{tabular}{llll}
\hline Group & $\begin{array}{l}\text { WKY-CON } \\
(n=6)\end{array}$ & $\begin{array}{l}\text { WKY-GN-vehicle } \\
(n=11)\end{array}$ & $\begin{array}{l}\text { WKY-GN-rhTM } \\
(n=11)\end{array}$ \\
\hline Urine volume, mL/day & $12.96 \pm 2.28$ & $26.36 \pm 2.22$ & $25.87 \pm 3.35$ \\
Urinary rhTM, pg/mL & 0 & 0 & $87.16 \pm 38.72$ \\
Loss of rhTM, $\mu \mathrm{g} /$ day & - & - & $2.44 \pm 1.03$ \\
\hline
\end{tabular}

Data are expressed as mean \pm SEM. CON, control; GN, glomerulonephritis; rhTM, recombinant human soluble thrombomodulin; WKY, Wistar-Kyoto. 
Kidney

Blood Pressure

Research
Kidney Blood Press Res 2020;45:391-406

DOI: $10.1159 / 000506286$

C) 2020 The Author(s). Published by S. Karger AG, Basel www.karger.com/kbr
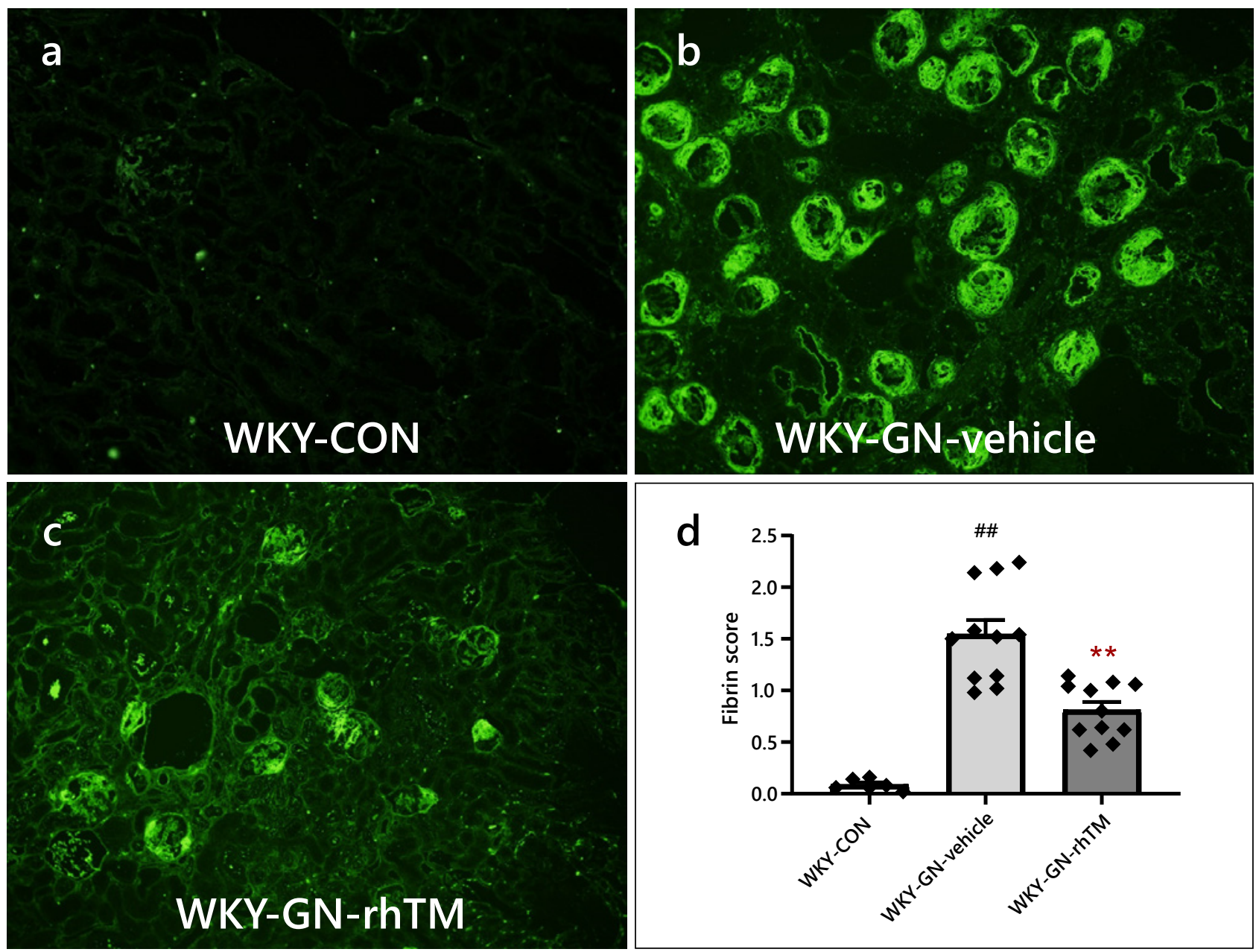

Fig. 4. Representative fibrin staining by immunofluorescence microscopy. a-c Immunofluorescent staining for fibrin in a WKY-CON rat (a), a WKY-GN-vehicle rat (b), and a WKY-GN-rhTM rat (c). d Semiquantitative assessment of fibrin deposition in each group. Each group contained 6 or 11 rats, and 50 glomeruli per rat were evaluated in a blinded manner. Data are expressed as mean \pm SEM. ${ }^{* *} p<0.01$ : WKY-GN-rhTM versus WKY-GN-vehicle rats; ${ }^{\# \#} p<0.01$ : WKY-GN-vehicle versus WKY-CON rats. CON, control; GN, glomerulonephritis; rhTM, recombinant human soluble thrombomodulin; WKY, Wistar-Kyoto.

rhTM Treatment Reduced Fibrin Depositions in Rats with Progressive Renal Failure

Prominent glomerular deposition was observed in WKY-GN-vehicle rats on day 56 (Fig. 4b). Semiquantitative evaluation of fibrin deposition showed a significantly reduced fibrin score in WKY-GN-rhTM rats compared with that in WKY-GN-vehicle rats (Fig. 4d).

\section{Effects of rhTM on Profibrogenic Gene and PARs Gene in Rats with Progressive Renal}

Failure

The gene expression levels of collagen type I, collagen type III, fibronectin, $\alpha \mathrm{SMA}$, and TGF- $\beta$ were much higher in WKY-GN-vehicle rats than in WKY-CON rats as assessed by realtime RT-PCR. Treatment with rhTM significantly attenuated these profibrogenic gene expressions. There was also an increase in gene expression for PARs in WKY-GN-vehicle rats compared with WKY-CON rats. Gene expressions for those receptors in rat kidneys were significantly decreased by rhTM treatment $(p<0.01)$ (Table 2$)$. 
Kidney

Blood Pressure

Research

Table 2. Expression of mRNA for profibrotic and PAR genes in the study groups

\begin{tabular}{l|l}
\hline Kidney Blood Press Res 2020;45:391-406 \\
\hline DOI: 10.1159/000506286 & $\begin{array}{l}\text { (c) 2020 The Author(s). Published by S. Karger AG, Basel } \\
\text { www.karger.com/kbr }\end{array}$ \\
\hline
\end{tabular}

Kanazawa et al.: Thrombomodulin Attenuates Renal Fibrosis

\begin{tabular}{lcc}
\hline Group & $\begin{array}{c}\text { WKY-GN-vehicle } \\
(n=11)\end{array}$ & $\begin{array}{c}\text { WKY-GN-rhTM } \\
(n=11)\end{array}$ \\
\hline Collagen I & $23.86 \pm 3.81^{\# \#}$ & $13.78 \pm 2.31^{*}$ \\
Collagen III & $7.46 \pm 0.88^{\# \#}$ & $4.84 \pm 0.78^{*}$ \\
Fibronectin & $154.63 \pm 13.68^{\# \#}$ & $130.91 \pm 10.45^{* *}$ \\
$\alpha$ SMA & $90.56 \pm 10.32^{\# \#}$ & $78.26 \pm 7.76^{*}$ \\
TGF- $\beta$ & $5.70 \pm 0.48^{\# \#}$ & $3.54 \pm 0.52^{* *}$ \\
PAR1 & $2.90 \pm 0.26^{\# \#}$ & $1.63 \pm 0.19^{* *}$ \\
PAR2 & $6.77 \pm 0.96^{\# \#}$ & $2.36 \pm 0.38^{* *}$ \\
\hline
\end{tabular}

Real-time RT-PCR for profibrotic and PAR gene levels in renal cortex. Data are expressed as mean \pm SEM. The values were normalized to GAPDH values and then expressed as relative quantification. CON, control; GN, glomerulonephritis; PAR, protease-activated receptor; rhTM, recombinant human soluble thrombomodulin; RT-PCR, reverse transcription polymerase chain reaction; WKY, Wistar-Kyoto. ${ }^{\#} p<$ 0.01: WKY-GN-vehicle versus WKY-CON rats. ${ }^{*} p<0.05,{ }^{* *} p<0.01$ : WKY-GN-rhTM versus WKY-GN-vehicle rats.
Table 3. Expression of mRNA for proinflammatory genes in the study groups

\begin{tabular}{lcc}
\hline Group & $\begin{array}{l}\text { WKY-GN-vehicle } \\
(n=11)\end{array}$ & $\begin{array}{l}\text { WKY-GN-rhTM } \\
(n=11)\end{array}$ \\
\hline TNF- $\alpha$ & $5.63 \pm 0.62^{\# \#}$ & $3.02 \pm 0.42^{* *}$ \\
IL-6 & $26.64 \pm 2.61^{\# \#}$ & $18.46 \pm 3.94^{\mathrm{NS}}$ \\
MCP-1 & $14.77 \pm 2.50^{\# \#}$ & $8.43 \pm 1.80^{*}$ \\
TLR2 & $5.95 \pm 0.65^{\# \#}$ & $4.67 \pm 0.63^{\mathrm{NS}}$ \\
TLR4 & $7.55 \pm 1.28^{\# \#}$ & $2.82 \pm 0.43^{* *}$ \\
MYD88 & $1.29 \pm 0.14^{\mathrm{NS}}$ & $0.77 \pm 0.05^{* *}$ \\
\hline
\end{tabular}

Real-time RT-PCR for proinflammatory gene levels in renal cortex. Data are expressed as mean \pm SEM. The values were normalized to GAPDH values and then expressed as relative quantification. GN, glomerulonephritis; MCP-1, monocyte chemoattractant protein 1; NS, not significant; rhTM, recombinant human soluble thrombomodulin; RT-PCR, reverse transcription polymerase chain reaction; TLR, Tolllike receptor; WKY, Wistar-Kyoto. NS, ${ }^{\# \#} p<0.01$ : WKY-GN-vehicle versus WKY-CON rats. NS, ${ }^{*} p<0.05,{ }^{* *} p<0.01$ : WKY-GN-rhTM versus WKY-GN-vehicle rats.

\section{Effects of rhTM on Proinflammatory Genes in Rats with Progressive Renal Failure}

TLRs have been identified and demonstrated to initiate proinflammatory signaling pathways. Since the TLR pathway and chronic inflammation participate in the pathogenesis of renal fibrosis, these were examined by real-time RT-PCR. The gene expression levels of TNF- $\alpha$, IL-6, MCP-1, TLR2, and TLR4 were much higher in WKY-GN-vehicle rats than in WKY-CON rats. Again, treatment with rhTM significantly decreased the gene expression levels of TNF- $\alpha(p<0.01)$, MCP-1 $(p<0.05)$, TLR4 $(p<0.01)$, and MYD88 $(p<0.01)$ (Table 3$)$.

\section{Effects of rhTM on MCP-1 in Rats with Progressive Renal Failure}

MCP-1 and macrophages are fundamental in the early pathogenesis of NTS-N. It is known that MCP-1 showed strong expression in glomeruli of rats with NTS-N on day 7 (Fig. 5b). To 

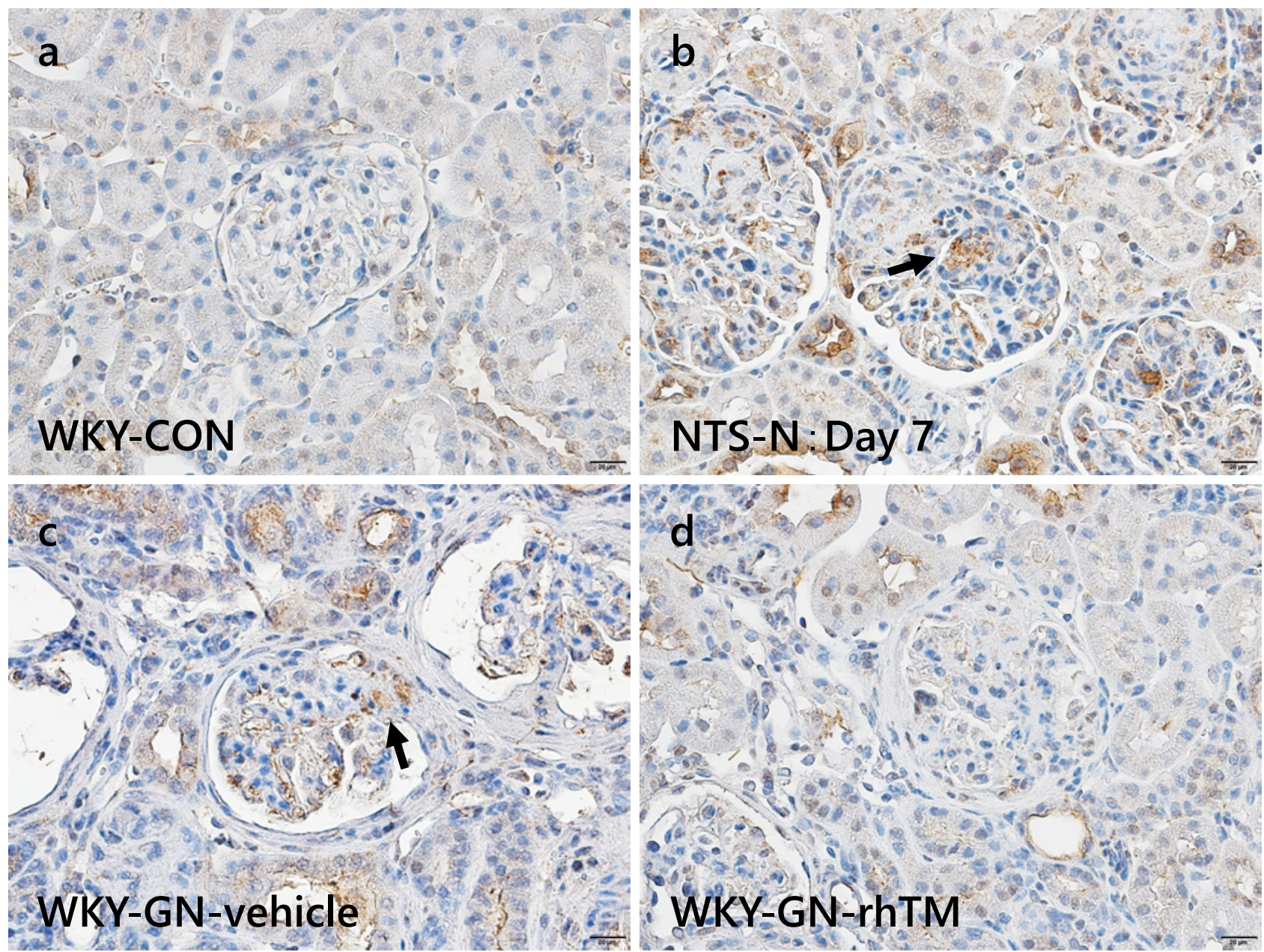

Fig. 5. Immunohistochemical analysis of MCP-1 expression in the study groups. a, c, d Representative pictures of kidney sections stained with immunohistochemistry for MCP-1 of a WKY-CON rat (a), a WKY-GNvehicle rat (c), and a WKY-GN-rhTM rat (d) on day 56. b The picture of kidney section of a rat with NTS-N on day 7 is shown as a positive control. a-d Original magnification, $\times 400$. CON, control; GN, glomerulonephritis; MCP-1, monocyte chemoattractant protein 1; NTS-N, nephrotoxic serum nephritis; rhTM, recombinant human soluble thrombomodulin; WKY, Wistar-Kyoto.

investigate the pathogenicity of MCP-1 and the efficacy of rhTM in rats with chronic phase of NTS-N, we performed immunostaining for MCP-1 on day 56 . Although MCP-1 protein was still detected in glomeruli of the WKY-GN-vehicle rats on day 56 (Fig. 5c), it was weaker than on day 7. MCP-1 expression had a tendency to be inhibited by long-term rhTM treatment (Fig. 5d).

Effects of rhTM on Proinflammatory and Profibrogenic Gene in Cultured Renal Fibroblasts

We investigated whether proinflammatory and profibrotic gene expression were increased in renal fibroblasts stimulated with thrombin. Stimulation with thrombin for $24 \mathrm{~h}$ increased the gene expression levels of IL-6, $\alpha$ SMA, and fibronectin, and these increases were significantly inhibited by pretreatment with rhTM in cultured rat renal fibroblasts (Fig. 6a-c). Furthermore, the gene expression levels of PARs were increased by stimulation with thrombin, and upregulation of PAR1 gene expression was significantly decreased by pretreatment with rhTM (Fig. 6d). Stimulation with thrombin did not significantly affect the gene expression levels of PAR2 (Fig. 6e). 


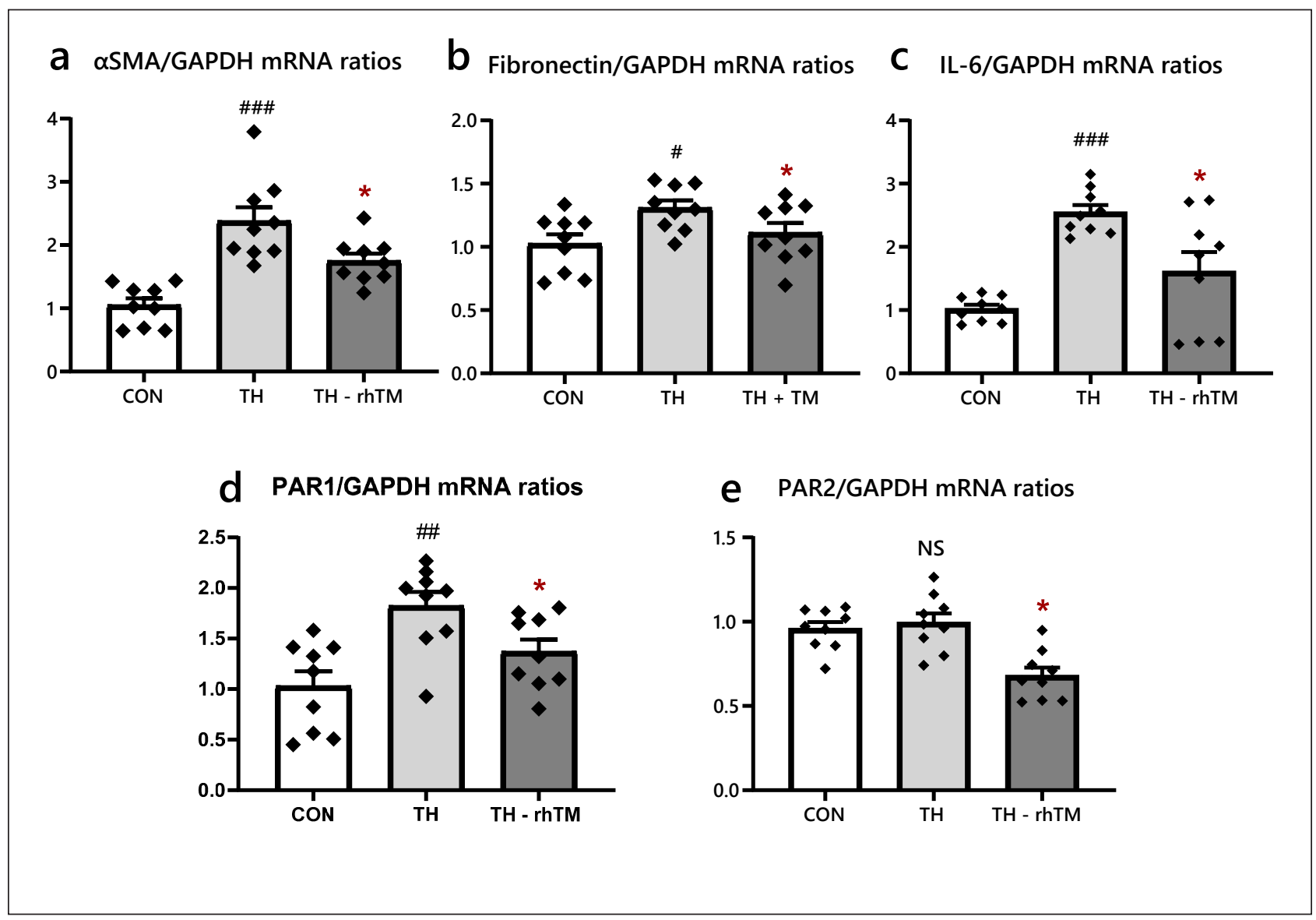

Fig. 6. Expression of mRNA in cultured renal fibroblasts pretreated with or without rhTM followed by stimulation with thrombin. Cells were pretreated with $\operatorname{rhTM}(2 \mu \mathrm{g} / \mathrm{mL})$ or saline for $1 \mathrm{~h}$, followed by stimulation with thrombin $(1 \mathrm{U} / \mathrm{mL}$ ) or $0.1 \%$ BSA for $24 \mathrm{~h}$. Real-time RT-PCR for $\alpha$ SMA (a), fibronectin (b), IL-6 (c), PAR1 (d), and PAR2 (e) in each group. Data are expressed as mean \pm SEM. NS, ${ }^{\#} p<0.05$, ${ }^{\# \#} p<0.01$, ${ }^{\# \# \# ~} p<0.001$ : control $(0.1 \%$ BSA $)$ versus thrombin; * $p<0.05$ : thrombin versus thrombin-rhTM. The results presented are representative of three independent experiments. NS, not significant; PAR1, protease-activated receptor 1; PAR2, protease-activated receptor 2; rhTM, recombinant human soluble thrombomodulin; RT-PCR, reverse transcription polymerase chain reaction.

\section{Discussion}

This study demonstrated that long-term treatment with rhTM attenuated renal disease progression in rats with crescentic GN, through effects against fibrosis and inflammation. Administration of rhTM to rats with anti-GBM nephritis was started 4 days after induction of nephritis, at a time when necrotizing crescentic GN was being established. With long-term treatment (from day 4 to day 55), rhTM showed protective effects by suppressing body weight loss, improving renal function as evaluated by serum Cr levels, attenuating the development of glomerulosclerosis and tubulointerstitial fibrosis, reducing fibrin deposition in glomeruli, and decreasing mRNA expressions of profibrotic genes (collagen type I, collagen type III, fibronectin, TGF- $\beta$, and $\alpha \mathrm{SMA}$ ). To the best of our knowledge, this is the first study to report antifibrotic effects of rhTM in GN.

The therapeutic potential of rhTM for kidney disease has been reported in rodent models of experimental renal ischemia-reperfusion injury $[25,26]$, thrombotic glomerular injury 


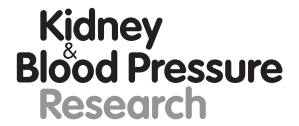

Kidney
Blood Pressure

Research \begin{tabular}{l|l}
\hline Kidney Blood Press Res 2020;45:391-406 \\
\hline DOI: 10.1159/000506286 & $\begin{array}{l}\text { @ 2020 The Author(s). Published by S. Karger AG, Basel } \\
\text { www.karger.com/kbr }\end{array}$ \\
\hline
\end{tabular}

Kanazawa et al.: Thrombomodulin Attenuates Renal Fibrosis

[27], and Shiga toxin-associated glomerular injury [28]. We have previously demonstrated that rhTM attenuated experimental crescentic GN in the early phase via anti-inflammatory effects [22]. Another recent report found that rhTM attenuated fibrotic changes in bleomycin-induced pulmonary fibrosis, which is pathologically characterized by extravascular and intra-alveolar thrombin activation and fibrin deposition following epithelial and endothelial injury [3]. In that study, thrombin induced expression of profibrotic proteins, and rhTM suppressed these changes via anti-inflammatory and anticoagulant functions. We thus expected that rhTM would prove suitable for treatment against the fibrotic phase of crescentic GN.

Several reports have provided insights into the relationship between the coagulation system and kidney disease [16]. Thrombin plays an important role in control of the coagulation system and also participates in numerous signaling mechanisms [17]. PARs are expressed on many types of renal cells and are activated by thrombin (PAR1, PAR3, PAR4) and trypsin/coagulation factor Xa (PAR2). Although these receptors are activated by different ligands, PAR2 is also activated by thrombin under certain conditions [29]. PAR1 and PAR2 are the most abundant receptors and play a role in inflammation or tissue remodeling. These receptors mediate the production of proinflammatory cytokines, such as IL-6 and IL-8 [30]. Furthermore, cross-talk occurs between PAR1/2 signaling and TGF- $\beta$ signaling, which links to tissue fibrosis $[31,32]$. PAR1/2 deficiency has been reported to be protective against experimental renal ischemia-reperfusion injury [33], crescentic GN [34], diabetic nephropathy $[35,36]$, and unilateral ureteral obstruction $[37,38]$. TM reportedly plays a role in PAR activation, with thrombin no longer converting fibrinogen to fibrin or activating PAR1 when it binds to the EGF-like domains of TM [1].

However, no reports have described antifibrotic effects of rhTM in kidney disease through the suppression of PAR signaling. In the present study, the mRNA expression of PAR1/2 was strongly increased in rats with crescentic GN, suggesting the involvement of PARs in the pathogenesis of progression to end-stage renal disease. Furthermore, a large amount of fibrin deposition in glomeruli was observed in rats with NTS-N on day 56. Acute and chronic inflammation was assumed to have induced expression of tissue factors that triggered the coagulation cascade, then thrombin induced dysfunction of glomerular cells, such as mesangial cells or endothelial cells, via PAR signaling, fibrin induction, and extracellular matrix accumulation. Thrombin does not activate and upregulate PAR2 in most cases, but has been reported to directly activate PAR2 at the high concentrations that can be achieved at the site of acute injury [29]. Receptors PAR1 and PAR2 were significantly increased in this study. We presume that inflammation resulting from glomerular injury secondarily activated and upregulated PAR2. Our results showed that rhTM had the potential to attenuate nephritis by reducing PAR1/2 signaling. In addition, it has been demonstrated that both thrombin inhibitor and factor Xa inhibitor had anti-inflammatory effects in a rodent model [30]. It was assumed that rhTM could outperform the specific inhibitor of thrombin in terms of therapeutic efficacy against renal fibrosis.

Progression of renal fibrosis is strongly associated with inflammatory response. We observed that administration of rhTM suppressed expression of TLR4, MYD88, TNF- $\alpha$, and MCP-1 in rats with NTS-N on day 56 . These results suggest that inhibition of the inflammatory response associated with TLRs may represent another mechanism by which rhTM attenuates renal fibrosis. We have previously demonstrated that rhTM reduced renal cortical proinflammatory cytokine expression in rats with NTS-N on day 7 [22]. In that study, we showed that rhTM potentially inhibited the HMGB1/TLR/MYD88 signaling pathway in NTS-N. HMGB1 is released from necrotic tissue or secreted by macrophages and is well known to bind to TLRs and mediate the release of proinflammatory cytokines. In addition, these TLRs have been identified and demonstrated to initiate not only proinflammatory signaling pathways, but 


\section{Kidney \\ Blood Pressure \\ Research}

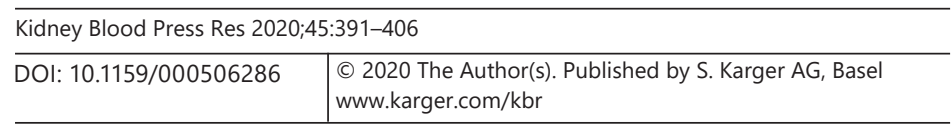

Kanazawa et al.: Thrombomodulin Attenuates Renal Fibrosis

also profibrotic pathways [39]. In particular, TLR4 deficiency was reported to be protective against renal fibrosis by reducing both $\alpha$ SMA protein expression and fibroblast accumulation $[40,41]$. Furthermore, proinflammatory cytokines play an important role in renal fibrosis. TNF $\alpha$ has been demonstrated to mediate obstruction-induced renal fibrosis [42]. IL-6 is a well-known proinflammatory cytokine and is also associated with fibrosis via STAT3 signaling [43]. Among inflammatory cytokines, especially, MCP-1 is the most common regulatory molecule of chronic inflammation and is considered to play an important role as a mediator of fibrocyte recruitment [8]. It is well known that MCP-1 plays an important role with the early pathogenesis of NTS-N. We detected the expression of MCP-1 protein on glomeruli in renal tissues of NTS-N on day 56. This is evidence that MCP-1 has some pathogenicity in the progression of crescentic GN also in the chronic phase.

The improvement of renal function and glomerulosclerosis/tubulointerstitial fibrosis could be explained as resulting from the protective effects of rhTM against glomerular damage by reducing PAR signaling or the TLR pathway. However, levels of urinary protein excretion, as an important marker of glomerular injury, were comparable between WKY-GN-vehicle rats and WKY-GN-rhTM rats throughout the study period. This result differs from our previous finding that rhTM significantly reduced proteinuria in the early stage of experimental GN [22]. Although rhTM has the potential to reduce podocyte apoptosis [44], the timing for starting treatment may be crucial to achieving protective effects on podocytes in vivo. Since the protective effects of rhTM on podocytes are largely unknown, further investigation is warranted.

Thrombin has been reported to stimulate proinflammatory, proliferative, and profibrogenic responses in rat mesangial cells [45, 46], human proximal tubular cells [47-49], and rat renal fibroblasts [50]. Resident fibroblasts in the kidney are considered to be key players for fibrosis and inflammation in the pathogenesis of chronic kidney disease [14,15, 51]. To clarify the mechanisms underlying the therapeutic effects of rhTM, we evaluated PAR activation in cultured rat renal fibroblasts stimulated by thrombin. We used pretreatment with rhTM in vitro examination because our protocol in vivo could intervene with the early phase of renal fibrosis, i.e., 4 days after the induction of nephritis. In this study, we showed that thrombin stimulation of NRK-49F cells significantly enhanced mRNA expression levels of $\alpha$ SMA, fibronectin, IL-6, and PAR1, and these upregulations were significantly reduced by pretreatment with rhTM. Thrombin was assumed to activate PAR1, then PAR signaling increased mRNA expression of profibrotic and proinflammatory genes. Accordingly, we consider that inhibition of the profibrotic and proinflammatory effects of thrombin via PAR signaling on fibroblasts is one of the important renoprotective mechanisms of rhTM.

Some limitations to this study exist. First, the systemic effects of rhTM have yet to be determined completely. Hruby et al. [52] showed that the parameter of hemostasis assessed on day 8 of NTS-N was clotting tendency. It has also been reported that chronic kidney disease patients had hypercoagulability, and it might be linked to the loss of renal TM [16]. Since rhTM has anticoagulant function by inhibiting thrombin, we evaluated plasma thrombin-antithrombin complex level to assess the activation of coagulation. In the present study, there was no significant difference in plasma thrombin-antithrombin complex level between WKY-GNvehicle rats and WKY-GN-rhTM rats (data not shown). It was speculated that the development of chronic phase of NTS-N is associated with renal-limited hypercoagulability. Second, the effect of rhTM on fibrinolysis has yet to be assessed, while we demonstrated the reduction of glomerular fibrin deposition in crescentic GN by rhTM. A previous study indicated that rhTM activated thrombin-activatable fibrinolysis inhibitor (TAFI), which inhibits fibrinolysis [53]. TAFI is activated by the thrombin-TM complex with a catalytic efficiency of 1,000-fold better than free thrombin alone. The renoprotective effect of TAFI is still incompletely understood $[54,55]$. Further studies will be needed. 


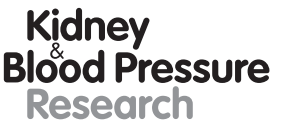

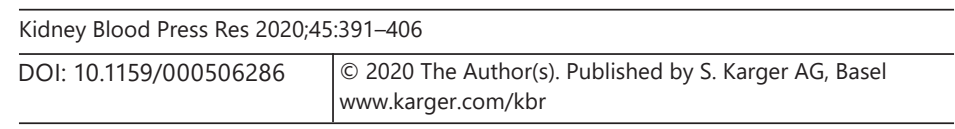

Kanazawa et al.: Thrombomodulin Attenuates Renal Fibrosis

In conclusion, we demonstrated that the coagulation system was involved in the fibrotic process of rats with NTS-N and that long-term rhTM treatment had therapeutic effects against the progression of crescentic GN. Inhibition of thrombin and PAR signaling seems important to the protective effects of rhTM. The results presented here suggest that rhTM may prove useful in limiting the progression of crescentic GN to end-stage renal disease.

\section{Acknowledgement}

We wish to thank Ms. Tomoko Suzuki for her excellent technical assistance. rhTM was kindly donated by Asahi Kasei Pharma Corp., which did not participate in the design, execution, or funding of this study.

\section{Statement of Ethics}

All animal protocols were compliant with the guidelines of the National Institutes of Health and met with the approval of the Animal Care Committee of Showa University in Tokyo.

\section{Disclosure Statement}

The authors have no conflicts of interest to disclose.

\section{Author Contributions}

N. Kanazawa and M. Iyoda designed the research. N. Kanazawa, S. Tachibana, K. Matsumoto, Y. Wada, T. Suzuki, and K. Iseri performed the research. N. Kanazawa and M. Iyoda analyzed the data. N. Kanazawa and M. Iyoda wrote the manuscript. T. Shibata approved the final version of the manuscript.

\section{References}

1 Loghmani H, Conway EM. Exploring traditional and nontraditional roles for thrombomodulin. Blood. 2018 Jul; 132(2):148-58.

2 Li YH, Kuo CH, Shi GY, Wu HL. The role of thrombomodulin lectin-like domain in inflammation. J Biomed Sci. 2012 Mar;19(1):34.

3 Kida T, Seno T, Nagahara H, Inoue T, Nakabayashi A, Kukida Y, et al. Roles of high-mobility group box 1 and thrombin in murine pulmonary fibrosis and the therapeutic potential of thrombomodulin. Am J Physiol Lung Cell Mol Physiol. 2018 Mar;314(3):L473-83.

4 Fujiwara K, Kobayashi T, Fujimoto H, Nakahara H, D’Alessandro-Gabazza CN, Hinneh JA, et al. Inhibition of Cell Apoptosis and Amelioration of Pulmonary Fibrosis by Thrombomodulin. Am J Pathol. 2017 Oct; 187(10): 2312-22.

5 Kataoka K, Taniguchi H, Kondoh Y, Nishiyama O, Kimura T, Matsuda T, et al. Recombinant Human Thrombomodulin in Acute Exacerbation of Idiopathic Pulmonary Fibrosis. Chest. 2015 Aug;148(2):436-43.

6 Isshiki T, Sakamoto S, Kinoshita A, Sugino K, Kurosaki A, Homma S. Recombinant human soluble thrombomodulin treatment for acute exacerbation of idiopathic pulmonary fibrosis: a retrospective study. Respiration. 2015;89(3):201-7.

7 Boor P, Ostendorf T, Floege J. Renal fibrosis: novel insights into mechanisms and therapeutic targets. Nat Rev Nephrol. 2010 Nov;6(11):643-56.

8 Tampe D, Zeisberg M. Potential approaches to reverse or repair renal fibrosis. Nat Rev Nephrol. 2014 Apr; 10(4):226-37. 


\begin{tabular}{l|l}
\hline \multicolumn{2}{l}{ Kidney Blood Press Res 2020;45:391-406 } \\
\hline DOI: 10.1159/000506286 & $\begin{array}{l}\text { C } 2020 \text { The Author(s). Published by S. Karger AG, Basel } \\
\text { www.karger.com/kbr }\end{array}$ \\
\hline
\end{tabular}

Kanazawa et al.: Thrombomodulin Attenuates Renal Fibrosis

9 Liu Y. Renal fibrosis: new insights into the pathogenesis and therapeutics. Kidney Int. 2006 Jan;69(2):213-7.

10 Howie AJ, Ferreira MA, Adu D. Prognostic value of simple measurement of chronic damage in renal biopsy specimens. Nephrol Dial Transplant. 2001 Jun;16(6):1163-9.

11 Wright JR, Duggal A, Thomas R, Reeve R, Roberts IS, Kalra PA. Clinicopathological correlation in biopsy-proven atherosclerotic nephropathy: implications for renal functional outcome in atherosclerotic renovascular disease. Nephrol Dial Transplant. 2001 Apr;16(4):765-70.

12 Kapitsinou PP, Ioannidis JP, Boletis JN, Sotsiou F, Nakopoulou L, Daphnis E, et al. Clinicopathologic predictors of death and ESRD in patients with pauci-immune necrotizing glomerulonephritis. Am J Kidney Dis. 2003 Jan; 41(1):29-37.

13 Nath KA. Tubulointerstitial changes as a major determinant in the progression of renal damage. Am J Kidney Dis. 1992 Jul;20(1):1-17.

14 LeBleu VS, Taduri G, O'Connell J, Teng Y, Cooke VG, Woda C, et al. Origin and function of myofibroblasts in kidney fibrosis. Nat Med. 2013 Aug;19(8):1047-53.

15 Mack M, Yanagita M. Origin of myofibroblasts and cellular events triggering fibrosis. Kidney Int. 2015 Feb; 87(2):297-307.

16 Madhusudhan T, Kerlin BA, Isermann B. The emerging role of coagulation proteases in kidney disease. Nat Rev Nephrol. 2016 Feb;12(2):94-109.

17 Palygin O, Ilatovskaya DV, Staruschenko A. Protease-activated receptors in kidney disease progression. Am J Physiol Renal Physiol. 2016 Dec;311(6):F1140-4.

18 McAdoo SP, Pusey CD. Anti-Glomerular Basement Membrane Disease. Clin J Am Soc Nephrol. 2017 Jul;12(7): 1162-72.

19 Shimizu A, Masuda Y, Mori T, Kitamura H, Ishizaki M, Sugisaki Y, et al. Vascular endothelial growth factor165 resolves glomerular inflammation and accelerates glomerular capillary repair in rat anti-glomerular basement membrane glomerulonephritis. J Am Soc Nephrol. 2004 Oct;15(10):2655-65.

20 Sheryanna A, Bhangal G, McDaid J, Smith J, Manning A, Foxwell BM, et al. Inhibition of p38 mitogen-activated protein kinase is effective in the treatment of experimental crescentic glomerulonephritis and suppresses monocyte chemoattractant protein-1 but not IL-1beta or IL-6. J Am Soc Nephrol. 2007 Apr;18(4):1167-79.

21 Iyoda M, Shibata T, Wada Y, Kuno Y, Shindo-Hirai Y, Matsumoto K, et al. Long- and short-term treatment with imatinib attenuates the development of chronic kidney disease in experimental anti-glomerular basement membrane nephritis. Nephrol Dial Transplant. 2013 Mar;28(3):576-84.

22 Tachibana S, Iyoda M, Matsumoto K, Wada Y, Suzuki T, Iseri K, et al. Recombinant human soluble thrombomodulin attenuates anti-glomerular basement membrane glomerulonephritis in Wistar-Kyoto rats through anti-inflammatory effects. Nephrol Dial Transplant. 2019 May;34(5):774-82.

23 Iyoda M, Shibata T, Kawaguchi M, Yamaoka T, Akizawa T. Preventive and therapeutic effects of imatinib in Wistar-Kyoto rats with anti-glomerular basement membrane glomerulonephritis. Kidney Int. 2009 May; 75(10):1060-70.

24 Kobayashi K, Shibata T, Sugisaki T. Aggravation of rat nephrotoxic serum nephritis by anti-myeloperoxidase antibodies. Kidney Int. 1995 Feb;47(2):454-63.

25 Sharfuddin AA, Sandoval RM, Berg DT, McDougal GE, Campos SB, Phillips CL, et al. Soluble thrombomodulin protects ischemic kidneys. J Am Soc Nephrol. 2009 Mar;20(3):524-34.

26 Ozaki T, Anas C, Maruyama S, Yamamoto T, Yasuda K, Morita Y, et al. Intrarenal administration of recombinant human soluble thrombomodulin ameliorates ischaemic acute renal failure. Nephrol Dial Transplant. 2008 Jan; 23(1):110-9.

27 Ikeguchi H, Maruyama S, Morita Y, Fujita Y, Kato T, Natori Y, et al. Effects of human soluble thrombomodulin on experimental glomerulonephritis. Kidney Int. 2002 Feb;61(2):490-501.

28 Suyama K, Kawasaki Y, Miyazaki K, Kanno S, Ono A, Ohara S, et al. The efficacy of recombinant human soluble thrombomodulin for the treatment of Shiga toxin-associated hemolytic uremic syndrome model mice. Nephrol Dial Transplant. 2015 Jun;30(6):969-77.

29 Mihara K, Ramachandran R, Saifeddine M, Hansen KK, Renaux B, Polley D, et al. Thrombin-Mediated Direct Activation of Proteinase-Activated Receptor-2: Another Target for Thrombin Signaling. Mol Pharmacol. 2016 May;89(5):606-14.

30 Sparkenbaugh EM, Chantrathammachart P, Mickelson J, van Ryn J, Hebbel RP, Monroe DM, et al. Differential contribution of FXa and thrombin to vascular inflammation in a mouse model of sickle cell disease. Blood. 2014 Mar;123(11):1747-56.

31 Chambers RC, Leoni P, Blanc-Brude OP, Wembridge DE, Laurent GJ. Thrombin is a potent inducer of connective tissue growth factor production via proteolytic activation of protease-activated receptor-1. J Biol Chem. 2000 Nov;275(45):35584-91.

32 Ungefroren H, Gieseler F, Kaufmann R, Settmacher U, Lehnert H, Rauch BH. Signaling Crosstalk of TGF- $\beta$ /ALK5 and PAR2/PAR1: A Complex Regulatory Network Controlling Fibrosis and Cancer. Int J Mol Sci. 2018 May; $19(6): 19$.

33 Sevastos J, Kennedy SE, Davis DR, Sam M, Peake PW, Charlesworth JA, et al. Tissue factor deficiency and PAR-1 deficiency are protective against renal ischemia reperfusion injury. Blood. 2007 Jan;109(2):577-83.

34 Cunningham MA, Rondeau E, Chen X, Coughlin SR, Holdsworth SR, Tipping PG. Protease-activated receptor 1 mediates thrombin-dependent, cell-mediated renal inflammation in crescentic glomerulonephritis. J Exp Med. 2000 Feb;191(3):455-62. 


\section{Kidney \\ Blood Pressure \\ Research}

\begin{tabular}{l|l}
\hline Kidney Blood Press Res 2020;45:391-406 \\
\hline DOI: 10.1159/000506286 & $\begin{array}{l}\text { @ 2020 The Author(s). Published by S. Karger AG, Basel } \\
\text { www.karger.com/kbr }\end{array}$ \\
\hline
\end{tabular}

35 Waasdorp M, Duitman J, Florquin S, Spek CA. Protease-activated receptor-1 deficiency protects against streptozotocin-induced diabetic nephropathy in mice. Sci Rep. 2016 Sep;6(1):33030.

36 Oe Y, Hayashi S, Fushima T, Sato E, Kisu K, Sato H, et al. Coagulation Factor Xa and Protease-Activated Receptor 2 as Novel Therapeutic Targets for Diabetic Nephropathy. Arterioscler Thromb Vasc Biol. 2016 Aug;36(8): 1525-33.

37 Rullier A, Gillibert-Duplantier J, Costet P, Cubel G, Haurie V, Petibois C, et al. Protease-activated receptor 1 knockout reduces experimentally induced liver fibrosis. Am J Physiol Gastrointest Liver Physiol. 2008 Jan; 294(1):G226-35.

38 Du C, Zhang T, Xiao X, Shi Y, Duan H, Ren Y. Protease-activated receptor-2 promotes kidney tubular epithelial inflammation by inhibiting autophagy via the PI3K/Akt/mTOR signalling pathway. Biochem J. 2017 Aug; 474(16):2733-47.

39 Yiu WH, Lin M, Tang SC. Toll-like receptor activation: from renal inflammation to fibrosis. Kidney Int Suppl (2011). 2014 Nov;4(1):20-5.

40 Campbell MT, Hile KL, Zhang H, Asanuma H, Vanderbrink BA, Rink RR, et al. Toll-like receptor 4: a novel signaling pathway during renal fibrogenesis. J Surg Res. 2011 Jun;168(1):e61-9.

41 Meldrum KK, Zhang H, Hile KL, Moldower LL, Dong Z, Meldrum DR. Profibrotic effect of interleukin-18 in HK-2 cells is dependent on stimulation of the Toll-like receptor 4 (TLR4) promoter and increased TLR4 expression. J Biol Chem. 2012 Nov;287(48):40391-9.

42 Meldrum KK, Misseri R, Metcalfe P, Dinarello CA, Hile KL, Meldrum DR. TNF-alpha neutralization ameliorates obstruction-induced renal fibrosis and dysfunction. Am J Physiol Regul Integr Comp Physiol. 2007 Apr; 292(4):R1456-64.

43 Ranganathan P, Jayakumar C, Ramesh G. Proximal tubule-specific overexpression of netrin-1 suppresses acute kidney injury-induced interstitial fibrosis and glomerulosclerosis through suppression of IL-6/STAT3 signaling. Am J Physiol Renal Physiol. 2013 Apr;304(8):F1054-65.

44 Yang SM, Ka SM, Wu HL, Yeh YC, Kuo CH, Hua KF, et al. Thrombomodulin domain 1 ameliorates diabetic nephropathy in mice via anti-NF- $\mathrm{B}$ /NLRP3 inflammasome-mediated inflammation, enhancement of NRF2 antioxidant activity and inhibition of apoptosis. Diabetologia. 2014 Feb;57(2):424-34.

45 Yamabe H, Osawa H, Inuma H, Kaizuka M, Tamura N, Tsunoda S, et al. Thrombin stimulates production of transforming growth factor-beta by cultured human mesangial cells. Nephrol Dial Transplant. 1997 Mar; 12(3):438-42.

46 Albrightson CR, Nambi P, Zabko-Potapovich B, Dytko G, Groom T. Effect of thrombin on proliferation, contraction and prostaglandin production of rat glomerular mesangial cells in culture. J Pharmacol Exp Ther. 1992 Oct;263(1):404-12.

47 Bae JS, Kim IS, Rezaie AR. Thrombin down-regulates the TGF-beta-mediated synthesis of collagen and fibronectin by human proximal tubule epithelial cells through the EPCR-dependent activation of PAR-1. J Cell Physiol. 2010 Oct;225(1):233-9.

48 Vesey DA, Cheung CW, Kruger WA, Poronnik P, Gobe G, Johnson DW. Thrombin stimulates proinflammatory and proliferative responses in primary cultures of human proximal tubule cells. Kidney Int. 2005 Apr;67(4): 1315-29.

49 Grandaliano G, Monno R, Ranieri E, Gesualdo L, Schena FP, Martino C, et al. Regenerative and proinflammatory effects of thrombin on human proximal tubular cells. J Am Soc Nephrol. 2000 Jun;11(6):1016-25.

50 Hewitson TD, Martic M, Kelynack KJ, Pagel CN, Mackie EJ, Becker GJ. Thrombin is a pro-fibrotic factor for rat renal fibroblasts in vitro. Nephron, Exp Nephrol. 2005;101(2):e42-9.

51 Sato Y, Yanagita M. Resident fibroblasts in the kidney: a major driver of fibrosis and inflammation. Inflamm Regen. 2017 Aug;37(1):17.

52 Hruby Z, Wendycz D, Kopeć W, Czerchawski L, Józefowiak M, Rabczyński J. Effect of antiproteolytic drugs: epsilon-aminocaproic acid (EACA) and aprotinin on experimental anti-GBM nephritis. Nephrol Dial Transplant. 1996 Jan;11(1):32-9.

53 Bajzar L, Manuel R, Nesheim ME. Purification and characterization of TAFI, a thrombin-activatable fibrinolysis inhibitor. J Biol Chem. 1995 Jun;270(24):14477-84.

54 Furugohri T, Shiozaki Y, Muramatsu S, Honda Y, Matsumoto C, Isobe K, et al. Different antithrombotic properties of factor Xa inhibitor and thrombin inhibitor in rat thrombosis models. Eur J Pharmacol. 2005 May; 514(1):35-42

55 Atkinson JM, Pullen N, Da Silva-Lodge M, Williams L, Johnson TS. Inhibition of Thrombin-Activated Fibrinolysis Inhibitor Increases Survival in Experimental Kidney Fibrosis. J Am Soc Nephrol. 2015 Aug;26(8):192537. 